\title{
LOST AND FOUND
}

\section{Sonia Lawrence*}

My reflections from the original symposium have been misplaced. They are inside a notebook I cannot find. The videotape of the day has been taped over. I do not remember what I said, probably because I have said too much in the interim. My thoughts, sentences, words, they happened, but they are lost.

When thinking about "Reigniting Critical Race" I think about my lost words. What does it mean to say "CRT as a lens is absent within the contemporary law school curriculum" when it is not absent, but unseen? I do not mean to suggest that anywhere in Canada, CRT infuses institutional approaches to curriculum or is a primary theoretical position for large numbers of scholars. But when the contemporary efforts to discuss CRT start from the premise that it is dead in curriculum, I confess to a feeling I cannot quite describe. I am afraid it is pique, but perhaps it is not. I think we should examine why we need to claim that the fire is dead. If we see a dead fire, what are we saying to those who write in the area, those who assign the work of Esmerelda Thornhill, Patricia, Monture, Sherene Razack and others? Was there a glorious past in which the flame burned brightly in the Canadian legal academy? Was critical race once a modish theoretical approach? Was it a radical movement crushed into conformity? I do not know whether any of these things are true, and like any student of law, I have spent quite some time fighting with the question - puzzling over the premise for this symposium and the vision that it creates of past and present. What are we struggling to regain, reignite, resurrect? What have we lost? What would it be like to find it?

When I was in my last year of law school, almost two decades ago now, one of my professors said to me, "While I was in Boston, I picked this up for you". She handed me a copy of The Alchemy of Race and Rights by Patricia Williams. She offered me a way in and a way out. In to the legal academy, the idea that it was possible to feel torn and yet be inside, to inhabit the structure as a host as we clawed and ate our way out, at least temporarily, out of the conviction that I was not quite right, was not good enough, was not qualified. But what critical race theory has brought to Canadian legal scholarship, Canadian law teaching and Canadian law is more complicated to assess. Many scholars have worked to adapt the analytical techniques and substantive principles of CRT into the Canadian context. But we cannot rely on critical race work done in the US, for three relatively obvious reasons: context, proof and praxis.

First, the contexts are and have always been, divergent; historically, demographically, legally. Critical race work in the US increasingly contends with two key "local" issues - the destruction of constitutional protections under a doctrine of colourblindness, and the assertion that the election of Obama is an indicator that the U.S. has become a post-racial society. These are critical issues. But they have a muted resonance in Canada. Obviously, they matter here. The elephant is moving - we feel that. Yet here in Canada we have a different context. Most significantly, perhaps, there is increased

\footnotetext{
* Osgoode Hall Law School
} 
recognition of the significance of the relationship between Canada and First Nations, a relationship which requires attention in Canadian critical race work (see, for instance, the work of Patricia Monture and Sherene Razack). This different context has historical roots, and contemporary inflections. What does colour blindness mean in Canada? How is it reflected in contemporary culture, or in substantive law? Even if American critical race theory has developed beyond a black \& white paradigm, it is not enough to enable wholesale transplantation. We need indigenous critical race work, work that starts from the contention that processes of racialization and racial subordination are enabled by law, and work that seeks to illustrate these processes in our history and practice. We have some of that work. We will always need more.

Second, and relatedly, critical race work which aims to produce legal results needs a form of proof. Canadian law's interest in equality is in most ways a comparative interest - an interest in discrimination rather than, for instance, economic equality. Usually, in discrimination/equality claims, that means a need for data which illustrates differential treatment. But the dearth of such data in doctrinally useful forms will surprise many observers. Some of the most egregious forms of racial inequality in this country will be extremely difficult to constitutionally challenge. The data do not exist, and will be costly, and perhaps impossible to develop. This is in part about context. A different history in Canada with respect to racial categories means different data collection practices. Refusal to recognize race can make it harder to document racial discrimination. Even taking into account the different timelines, Canada has a very slim body of race jurisprudence compared to the U.S. despite having constitutional protections against racial discrimination since 1982. Where are the cases? Even the existence of Human Rights codes, tribunals and commissions cannot fully explain why there are no section 15 (equality) cases on race from the Supreme Court of Canada, with the exception of a few recent cases which treat (I would say very wrongly) band membership as a racial categorization.

Finally, critical race is praxis. One of the key insights of critical race theory, building on critical theory more generally, is the recognition of the definitional power contained not only in legal analysis but of legal practice. Critical race action requires attention to communities of non scholars communities of racialized people with intimate knowledge of oppression and discrimination. These communities must determine priorities, strategies, opportunities, not have these determined by legal scholars and practitioners who have come up with a workable doctrinal argument. Crucially, critical race praxis will require developing allies and coalitions, in terms of law and politics. These complicated discussions require that local communities are heard. I do not mean to suggest that this is not being done in Canada, but rather am pointing out one more reason that we are unable to rely on American work. How will various racialized peoples participate in racial discrimination claims in the context of immigration, of colonialism and indigenous rights, of policing? How are communities differently situated and defined? How can we define the community of interest, and the conflicts between these groups? In these struggles, we should recognize the uniqueness of our situation, and the need for local debate, local participation and local solutions.

These differences between the U.S. and Canada are not intended to suggest that American work on race offers us nothing. But it is intended to suggest that harking too often to the U.S. leads us into more complications. As an example, when we treat Brown v. Board of Education as a touchstone, we may imply that racial segregation in schools is in the past and that law vanquished it. American critical race scholarship can help question some of those assumptions. But it cannot illustrate the historical approaches to segregation in schooling in Canada (which differed considerably by location), nor the contemporary realities of de facto segregation. When those of us in Canada consider where to put our critical race energy, we can consider these three categories. We can ask where we are best suited to 
serve. We can ask what has gone before and what is available now. Then we can embrace the paradox of finding comfort in a vision which pulls apart the tightly knit structures of legal power even though it is those structures which constitute our specialised knowledge and expertise. 